\title{
CLINICAL PROFILE OF AETIOLOGICAL AND RISK FACTORS IN YOUNG STROKE
}

\author{
R. Ramesh', G. Sree Ranga Lakshmi², S. Narmada ${ }^{3}$, K. Suma $^{4}$, B. Tirumala Rao ${ }^{5}$, M. Deepti Kiran' ${ }^{6}$, K. Kiran Kumar7, P. Vijayalakshmi ${ }^{8}$
}

${ }^{1}$ Assistant Professor, Department of Neurology, Osmania Hospital, Hyderabad, Telangana.

${ }^{2}$ Associate Professor, Department of Neurology, Osmania Hospital, Hyderabad, Telangana.

${ }^{3}$ Post Graduate, Department of Neurology, Osmania Hospital, Hyderabad, Telangana.

${ }^{4}$ Senior Resident, Department of Neurology, Osmania Hospital, Hyderabad, Telangana.

5 Post Graduate, Department of Neurology, Osmania Hospital, Hyderabad, Telangana.

${ }^{6}$ Post Graduate, Department of Neurology, Osmania Hospital, Hyderabad, Telangana.

${ }^{7}$ Post Graduate, Department of Neurology, Osmania Hospital, Hyderabad, Telangana.

${ }^{8}$ Post Graduate, Department of Neurology, Osmania Hospital, Hyderabad, Telangana.

ABSTRACT

\section{BACKGROUND}

Stroke constitutes a significant health problem in paediatric population. The reported incidence of childhood stroke is 2-6/100000 children per year in the past 10 years. The impact of childhood stroke can easily be realised in terms of economic, social and psychological burden related to disability of affected children and long-term sequelae that include social and economic sequences as well as neurologic and cognitive disabilities and epileptic disorders. The identification of aetiology and risk factors of childhood stroke is important as many of these are age and population specific. Brain infarcts and brain haemorrhages are significantly less common in patients younger than 20 years as compared to adult patients older than 65 years; and their clinical aetiologies also differ markedly from older patients. The risk factors of young stroke include congenital cardiac defects, cerebral vascular defects and various genetic and metabolic disorders. The commonest aetiologies in developed countries encompasses cerebral arteriopathies, congenital or acquired cardiac disease and serious systemic infections. Haematological factors such as thrombophilias also contribute. The commonest CNS infections associated with stroke can be categorised into viral, bacterial, parasitic and fungal in origin. Metabolic factors, AVM and intracranial aneurysm are also potential risk factors. There is no population based published data about the incidence or prevalence of paediatric stroke in India. In the hospital based studies from India, paediatric strokes have constituted less than $1 \%$ of all paediatric admissions and 5-10\% of all stroke. We attempted to study the clinical profile and risk factors of childhood stroke in South Indian population attending our hospital.

\section{KEYWORDS}

Young Stroke, Hypercoagulable States.

HOW TO CITE THIS ARTICLE: Ramesh R, Lakshmi GSR, Narmada S, et al. Clinical profile of aetiological and risk factors in young stroke. J. Evolution Med. Dent. Sci. 2016;5(54):3629-3632, DOI: 10.14260/jemds/2016/836

\section{INTRODUCTION}

A stroke is defined as rapidly developing clinical symptoms and/or signs of focal, and at times global (applied to patients in deep coma and to those with subarachnoid haemorrhage) loss of brain function with symptoms lasting more than 24 hours or leading to death with no apparent cause other than that of vascular origin.

Stroke can be ischaemic, haemorrhagic, or both. Ischaemic stroke is more frequently caused by arterial occlusion, but it may also be caused by venous occlusion of cerebral veins or sinuses.(1) Haemorrhagic stroke is the result of bleeding from a ruptured cerebral artery or from bleeding into the site of an Acute Ischaemic Stroke (AIS).(1)

AIS accounts for about half of all strokes in children in contrast to adults in whom $80-85 \%$ of all strokes are ischaemic. $(1,2)$

The reported incidence of combined ischaemic and haemorrhagic paediatric stroke ranges from 1.2 to 13 cases per 100,000 children under 18 years of age.(2)

Financial or Other, Competing Interest: None.

Submission 16-06-2016, Peer Review 28-06-2016,

Acceptance 02-07-2016, Published 07-07-2016.

Corresponding Author:

Dr. R. Ramesh,

Assistant Professor,

Department of Neurology,

Osmania Hospital,

Hyderabad, Telangana.

E-mail: ramrameshneuro@gmail.com

DOI: $10.14260 /$ jemds/2016/836
However, paediatric stroke is likely more common than we may realize, since it is thought to be frequently undiagnosed or misdiagnosed. This may be due to a variety of factors including a low level of suspicion by the clinician and patients who present with subtle symptoms that mimic other diseases. This, in turn, can lead to a delay in the diagnosis of stroke.(1)

The reported annual incidence of cerebral infarction in children all over the world varies between 1.2 per 100,00 to 2.7 per 100,000 .(3) About $20-30 \%$ of all infants of less than 35 weeks gestational age have intraventricular or germinal matrix haemorrhage. For reasons not clear, a high prevalence of childhood stroke has been reported from France and Saudi Arabia.

There is no population based published data about the incidence or prevalence of paediatric stroke in India. In the hospital based studies from India, paediatric strokes have constituted less than $1 \%$ of all paediatric admissions and 5$10 \%$ of all stroke.

Haemorrhagic strokes ranged between 1.5 and 5 per 100,000 children per year. $(3,4)$ and estimates of ischaemic strokes ranged between 1.2 and 8 per 100,000 children per year. $(3,5)$

\section{MATERIALS AND METHODS}

This is the descriptive cross-sectional study conducted in the age group between 1 year and 18 years. Children with sudden onset of focal neurological deficit who were brought to Neurology OPD at Osmania General Hospital and those 
referred from Niloufer Children Hospital during the period between September 2013 and January 2016 were included.

\section{Inclusion Criteria}

1. Patients with new-onset stroke.

2. Patients from 1 year to 18 years of age were included in the study.

\section{Exclusion Criteria}

1. Patients more than 18 years of age were excluded.

2. Those with drop attacks and loss of consciousness due to other causes were excluded.

3. Children with head injuries were excluded.

The procedure was explained to and informed consent was taken from the parents or guardians. Patient's age, sex and detailed history were taken. Detailed neurological examination was done. Basic investigations like Haemogram, ESR, Serum electrolytes, Blood sugars, Renal functions, Complete urine examination, sickling test, Imaging (CT brain, MRI brain) were done in all patients. Protein-C and $S$, Antithrombin III and Homocysteine levels, ECG, 2D Echo Connective tissue profile, CSF analysis, MR Venography and MR angiography were done in selected patients according to clinical scenario. The data was analysed and tabulated. Chisquare test was used for statistical analysis.

\section{OBSERVATIONS AND RESULTS}

Eighty eight children met with inclusion criteria and were included in the study. Among them, 48 were male children and 40 were female children.

\begin{tabular}{|c|c|c|}
\hline Gender & Total & Percentage \\
\hline Male & 48 & $54.55 \%$ \\
\hline Female & 40 & $45.45 \%$ \\
\hline Total & $\mathbf{8 8}$ & \\
\hline \multicolumn{3}{|c|}{ Table 1: Gender Distribution } \\
\hline
\end{tabular}

\begin{tabular}{|c|c|c|c|c|}
\hline Age & $\begin{array}{c}\text { Male } \\
\text { Children }\end{array}$ & $\begin{array}{c}\text { Female } \\
\text { Children }\end{array}$ & Total & Percentage \\
\hline $\begin{array}{c}1 \text { yr. }- \\
4 \text { yrs. }\end{array}$ & $\begin{array}{c}30 \\
(57.69 \%)\end{array}$ & $\begin{array}{c}22 \\
(42.3 \%)\end{array}$ & 52 & $59.2 \%$ \\
\hline $\begin{array}{c}5 \text { yrs. - } \\
7 \text { yrs. }\end{array}$ & $\begin{array}{c}15 \\
(53.57 \%)\end{array}$ & $\begin{array}{c}13 \\
(46.42 \%)\end{array}$ & 28 & $31.81 \%$ \\
\hline $\begin{array}{c}8 \text { yrs. - } \\
10 \text { yrs. }\end{array}$ & $\begin{array}{c}1 \\
(33.3 \%)\end{array}$ & $\begin{array}{c}2 \\
(66.66 \%)\end{array}$ & 3 & $3.4 \%$ \\
\hline $\begin{array}{c}11 \text { yrs. }- \\
18 \text { yrs. }\end{array}$ & $\begin{array}{c}2 \\
(40 \%)\end{array}$ & $\begin{array}{c}3 \\
(60 \%)\end{array}$ & 5 & $5.68 \%$ \\
\hline \multicolumn{5}{|c|}{ Table 2: Age and Gender Distribution } \\
\hline
\end{tabular}

Majority of the children (52, that is $59.2 \%$ ) were below 4 years of age and the $p$ value was less than 0.05 is statistically significant. (Chi-square $=33$, degree of freedom $(d f)=2, p$ value $=0.05$ ). In our study among children of less than 7 years of age, the incidence of stroke was more common in boys when compared to girls. In older children, the incidence of stroke was more common in girls.

\begin{tabular}{|c|c|c|c|c|}
\hline Type & Male & Female & Total & Percentage \\
\hline AIS & 46 & 39 & 85 & $96.59 \%$ \\
\hline CSVT & 1 & - & 1 & $1.13 \%$ \\
\hline IC bleed & 1 & 1 & 2 & $2.27 \%$ \\
\hline \multicolumn{5}{|c|}{ Table 3: Type of Stroke } \\
\hline
\end{tabular}

Most common type of stroke seen in our study was arterial ischaemic stroke followed by IC bleed and CSVT.

\begin{tabular}{|c|c|c|c|}
\hline Age & AIS & CSVT & IC Bleed \\
\hline 1 yr. - 4 yrs. & $52(61.1 \%)$ & - & - \\
\hline 5 yrs. - 7 yrs. & $27(31.7 \%)$ & - & $1(3.54 \%)$ \\
\hline 8 yrs. - 10 yrs. & $2(2.35 \%)$ & - & $1(33.3 \%)$ \\
\hline $\begin{array}{c}11 \text { yrs. }-18 \\
\text { yrs. }\end{array}$ & $4(4.7 \%)$ & $1(20 \%)$ & - \\
\hline Total & $\mathbf{8 5}$ & $\mathbf{1}$ & $\mathbf{2}$ \\
\hline \multicolumn{3}{|c|}{ Table 4: Age and Type of Stroke } \\
\hline
\end{tabular}

Majority of the children of ischaemic stroke belong to 1-4 years' age group followed by 5-7 years' age group. CSVT was seen in older children. IC bleed was seen in children from 5 to 10 years of age group.

\begin{tabular}{|c|c|c|c|c|c|}
\hline $\begin{array}{c}\text { Type of } \\
\text { Circulation }\end{array}$ & $\begin{array}{c}\mathbf{1} \text { yr. - } \\
\mathbf{4} \text { yrs. }\end{array}$ & $\begin{array}{c}\mathbf{5 - 7} \\
\text { yrs. }\end{array}$ & $\begin{array}{c}\mathbf{8 - 1 0} \\
\text { yrs. }\end{array}$ & $\begin{array}{c}\mathbf{1 1 - 1 8} \\
\text { yrs. }\end{array}$ & Total \\
\hline Anterior & 52 & 28 & 2 & 4 & 86 \\
\hline Posterior & - & - & 1 & 1 & 2 \\
\hline Mixed & - & - & - & - & - \\
\hline \multicolumn{6}{|c|}{ Table 5: Age and Type of Circulation } \\
\hline
\end{tabular}

In our study, anterior circulation strokes are more common than posterior circulation strokes. Anterior circulation strokes are seen in 86 children, while posterior circulation strokes are seen in only two children.

Among patients with anterior circulation stroke, fifty two children were less than 4 years of age and twenty seven children were in 5-7 years of age group. Two children were in 8-10 years' group and four children were in 11-18 years of age group; 1-4 years' age group was the most affected age group followed by 3-7 years.

Posterior circulation stroke was seen in 2 children. Among them, one child was in 8-10 years of age group and other child in 11-18 years of age group.

The MCA territory was the most commonly involved terrritory seen in 86 children out of 88 patients. All the 52 patients in the 1-4 years' group and 27 patients in the 5-7 years had involvement of MCA territory.

Two patients in the 8-10 years' group had MCA involvement and 1 had PCA involvement. Four patients in the 11-18 years' group had MCA involvement, while one patient had PCA involvement.

\begin{tabular}{|c|c|}
\hline $\begin{array}{c}\text { Clinical } \\
\text { Presentation }\end{array}$ & $\begin{array}{c}\text { Number of } \\
\text { Children }\end{array}$ \\
\hline Hemiparesis & 86 \\
\hline Quadriparesis & - \\
\hline Monoparesis & - \\
\hline Cerebellar Signs & 1 \\
\hline $\begin{array}{c}\text { Dystonia and Involuntary } \\
\text { Movements }\end{array}$ & - \\
\hline Pseudobulbar Palsy & - \\
\hline Visual Impairment & - \\
\hline Cranial Nerve Involvement & 1 \\
\hline Total & $\mathbf{8 8}$ \\
\hline Table 6: Clinical Presentation \\
\hline
\end{tabular}

Eighty six children presented with hemiparesis. One child presented with cerebellar features. One child presented with 
third and fourth cranial nerve involvement (Brainstem involvement).

\begin{tabular}{|c|c|c|}
\hline Aetiology & $\begin{array}{c}\text { Male } \\
\text { Children }\end{array}$ & $\begin{array}{c}\text { Female } \\
\text { Children }\end{array}$ \\
\hline $\begin{array}{c}\text { Hypercoagulable } \\
\text { State }\end{array}$ & 25 & 20 \\
\hline Infections & 19 & 12 \\
\hline SLE & - & 3 \\
\hline IC bleed & 1 & 1 \\
\hline Cardiac & 2 & 2 \\
\hline Metabolic & - & 2 \\
\hline Dissection & 1 & - \\
\hline Total & $\mathbf{4 8 ~ ( 5 4 . 5 4 \% )}$ & $\mathbf{4 0}$ (45.45\%) \\
\hline \multicolumn{2}{|c|}{ Table 7: Aetiology } \\
\hline
\end{tabular}

In our study, hypercoagulable state was the most common cause for stroke in children. Among them, protein $\mathrm{C}$ and $\mathrm{S}$ deficiency was seen in 28 children. Out of these 28 children, 18 were male and 10 were female. Most common age group affected was 1-4 years.

Homocystinaemia was seen in 17 children. Among them 14 were male children and 3 were female children. Most common affected age group was 1-4 years followed by 5-7 years' age group.

Next most common cause was infection, seen in 19 male and 12 female children.

Systemic Lupus Erythematosus (SLE) was seen in three female children.

Cardiac disease was the cause in 4 children. Among them 2 were male and 2 were female. One male child and one female child were affected with Tetralogy of Fallot (TOF) and one male child had dilated cardiomyopathy and one female child had tricuspid atresia for which Fontan surgery is done.

Metabolic aetiology was seen in 2 female children. Among them, one child was affected with diabetes and one child had mitochondrial disease. Internal carotid arterial dissection was seen in one male child.

\section{DISCUSSION}

Stroke, once thought to be rare in paediatric population, is now becoming increasingly recognised. Paediatric stroke leads to significant morbidity and mortality. Roughly $10-25 \%$ of children with a stroke will die and up to $25 \%$ of children will have a recurrence, and up to $66 \%$ will have persistent neurological deficits or develop subsequent seizure disorders, learning or developmental problems. Given the onset of impairment during childhood and the effect on quality of life for the child and family, the economic and emotional costs to society are amplified.(6)

Childhood strokes are not uncommon in India. The incidence is increasing due to increasing life expectancy due to cardiac causes, connective tissue disorders. The causes are different from adults. Early diagnosis of stroke in young children is difficult.(7)

In our prospective observational study, stroke is found to be more common in male children below 7 years of age and above seven years of age girls were more affected.

In Saima Bee et al (2011). ${ }^{(8)}$ study from Pakistan, the most common aetiology was infection (67.39\%) followed by microcytic hypochromic anaemia $(60.86 \%)$. Cardiac causes were seen in $8.6 \%$ followed by dehydration and hypertension.
In our study, hypercoagulable state was the most common cause followed by infections. Anaemia and dehydration were not reported in contrast to Saima study. Cardiac causes are less in our study when compared to Saima study.(8) In Saima's study both the sexes are equally involved, whereas in our study male children are slightly more affected (54.54\%) when compared to female children (45.45\%) in younger age group and girls are more affected in older age group. Most common age of presentation seen in Saima study is less than 4 years, which is similar to our study. Majority of the children presented with limb weakness, which was similar to our study.

Hypercoagulable state was more common cause of stroke, seen in 45 children (51.13\%) followed by infections in 31 cases (35.22\%).

In a study from SGPGI Lucknow (Jayantee Kalita et al, 2012).(9) in 79 children, arterial ischaemic stroke is the most common cause $(78.5 \%)$ of childhood stroke and infections were the most common aetiology followed by cardio embolism and hypercoagulable states.

In a study from western Rajasthan (Manish Parakh et al, 2015).(10) male children were mostly affected with stroke (64\%) similar to our study (54.54\%). Most common age of presentation in their study was less than 4 years, which was similar to our study. Ischaemic strokes were the most common type of stroke (74\%), similar to our study (96.59\%). CSVT was seen in $8 \%$ of children, whereas in our study it was seen in $1.13 \%$. IC bleed was seen in $6 \%$ of the children, where in our study it was seen in $2.27 \%$.

In a study from Kolkata (Chaitali Patra et al, 2015).(11) infections $(41.4 \%)$ were the most common cause of stroke in children followed by hypercoagulable states $(11.8 \%)$. Arterial ischaemic stroke was the most common cause (91.2\%) similar to our study. Most common presentation was Hemiparesis, similar to our study. Among sex distribution, male children were slightly more affected when compared to female children, which was similar to our study.

In contrast to our study, studies by Lee et al (2012).(12) showed vasculopathy (35.5\%) as the commonest cause and intracranial infection were the $4^{\text {th }}$ in frequency in their study.

Another Asian study by Lee et al (2008).(13) also showed vascular aetiology (33\%) as commonest and Intracranial infection was found to be next most common.

Vomiting, altered consciousness and fever were found to be significantly associated with stroke patients with infectious aetiologies, focal neurological deficit (Hemiparesis) was mostly associated with non-infectious aetiology, while other clinical presentations (e.g. Aphasia, Cranial Nerve Palsy, Headache) had no significant association with aetiology. This type of data relating to the association of stroke symptoms with aetiology was lacking in most of the Asian literature. Analysing California Hospital discharge data for a 10-year interval for children 1 month through 19 years of age, Fullerton and Colleagues estimated the stroke incidence to be 2.3 per 100,000 children per year $(1.2$ per 100,000 per year for ischaemic lesions and 1.1 per 100,000 per year for haemorrhagic lesions). Boys were at higher risk than girls and black children were at higher risk than White and Asian children, even after adjustment for trauma and the presence of Sickle Cell Disease.(14)

A study of Chinese children in Hong Kong found a similar overall stroke risk ( 2.1 per 100,000 per year), but only $28 \%$ of those children had haemorrhagic strokes, peak age for both 
ischaemic stroke and intraparenchymal brain haemorrhage was the first year of life with a third of the cases presenting in this age group, whereas SAH was more common among teenagers. There also appears to be an excess of strokes in boys and in those of black ethnicity; this excess was not fully explained by the prevalence of SCD in this population.(15)

\section{CONCLUSIONS AND SUMMARY}

Stroke in paediatric population is now a recognised entity associated with long-term morbidity and disability. There is a high prevalence of multiple risk factors. Every child with stroke must be thoroughly assessed using haematologic, biochemical, neuroimaging and metabolic studies. Identification of risk factors is imperative, so as to guide appropriate interventions aimed at preventing the development of childhood strokes.

To find out the aetiology, extensive work-up is necessary. History of trivial trauma is also important as the mineralising angiopathy is an important cause for strokes around 6-24 months' age group of children.

Work-up for cardiac causes, connective tissue diseases are necessary in all children. If still aetiology was not able to identify, metabolic work-up may be helpful. Evaluation of risk factors are important to tell the prognosis to their parents.

\section{REFERENCES}

1. Giroud M, Lemesle M, Gouyon JB, et al. Cerebrovascular disease in children under 16 years of age in the city of Dijon, France: a study of incidence and clinical features from 1985 to 1993. J Clin Epidemiol 1995;48(11): 1343-8.

2. Gandhi SK, McKinney JS, Sedjro JE, et al. Temporal trends in incidence and long-term case fatality of stroke among children from 1994 to 2007. Neurology 2012;78(24):1923-9.

3. Roach ES. Stroke in children. Curr Treat Options Neurol 2000;2:295-304.
4. Ganesan V, Prengler M, McShane MA, et al. Investigation of risk factors in children with arterial ischaemic stroke. Ann Neurol 2003;53(2):167-73.

5. Cnossen MH, Aarsen FK, Akker S, et al. Paediatric arterial ischaemic stroke: functional outcome and risk factors. Dev Med Child Neurol 2010;52(4):394-9.

6. Lanthier S, Carmant L, David M, et al. Stroke in children: the coexistence of multiple risk factors predicts poor outcome. Neurology 2000;54(2):371-8.

7. DeVeber GA, MacGregor D, Curtis R, et al. Neurologic outcome in survivors of childhood arterial ischaemic stroke and sinovenous thrombosis. Journal of Child Neurology 2000;15(5):316-24.

8. Bibi S, Gilani SY, Shah SR, et al. Childhood strokes: epidemiology, clinical features: a descriptive crosssectional study. J Ayub Med Coll Abbottabad 2011;23(2):69-71.

9. Kalita J, Goyal G, Misra UK. Experience of paediatric stroke from a tertiary medical centre in North India. J Neurol Sci 2013;325(1-2):67-73.

10. Parakh M, Arora V, Khilery B. A prospective study evaluating the clinical profile of paediatric stroke in western Rajasthan. J Neurol Disord 2014;2(6).

11. Patra C, Sarkar S, Guha D, et al. Clinico-aetiological profile of childhood stroke in a tertiary care hospital in eastern India. Neurosci Rural Pract 2015;6(4):515-9.

12. Lee EH, Yum MS, Ko TS. Risk factors and clinical outcomes of childhood ischaemic stroke in a single Korean tertiary care centre. J Child Neurol 2012;27(4):485-91.

13. Lee YY, Lin KL, Wang HS, et al. Risk factors and outcomes of childhood ischaemic stroke in Taiwan. Brain Dev 2008;30(1):14-9.

14. Fullerton HJ, Elkins JS, Johnston SC. Paediatric stroke belt: geographic variation in stroke mortality in US children. Stroke 2004;35(7):1570-3.

15. Chung B, Wong V. Paediatric stroke among Hong Kong Chinese subjects. Paediatrics 2004;114(2):e206-12. 